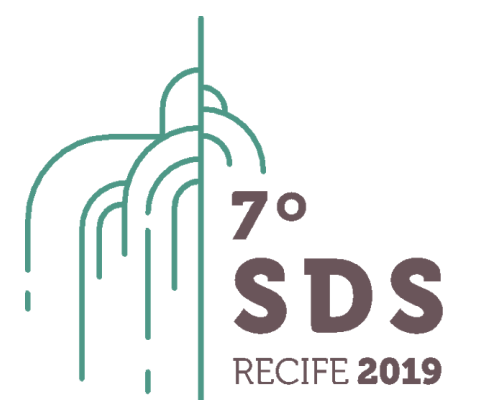

SIMPÓSIO SUSTAINABLE

DESIGN DESIGN

SUSTENTÁVEL SYMPOSIUM

\title{
Contribuições do Design para o cenário econômico criativo local em Caruaru-PE: $O$ caso do Coletivo Fé, menina.
}

\author{
Bianca Caroline Carvalho da Silva', Tamires Maria de Lima Silva² \\ 1Universidade Federal de Pernambuco, Graduada em Design, bianca.infinitocriativo@gmail.com \\ ${ }^{2}$ Universidade Federal de Pernambuco, Mestra em Design, tamiresdesigner@outlook.com
}

Resumo. Esse artigo apresenta reflexões sobre possíveis contribuições do design para novos formatos de negócios ligados à criatividade e inovação, tomando como base o entendimento das mudanças vivenciadas localmente, na cidade de Caruaru-PE, diretamente ligadas ao cenário do empreendedorismo pelo viés da economia criativa e desse modo as atuais condições para posicionar e validar negócios ligados a esses conceitos no contexto local. Para tanto será apresentado em detalhes o Projeto Fé, Menina; fundado há 3 anos em Caruaru para unir e fortalecer marcas, idealizadas e geridas por mulheres empreendedoras, que tem em seu cerne o desenvolvimento de produtos ou serviços ligados a criatividade e expressão de significados, fortalecendo o posicionamento dessas empresas para além do objetivo de comercializar. Na construção dessa pesquisa foi realizado um levantamento de dados ligados ao estado da arte do tema proposto, para o entendimento da relevância dos principais pilares ligados ao movimento econômico criativo atual e ao design e suas vertentes: Design Estratégico e Design Social. Desenvolveu-se uma reflexão sobre o entendimento das possíveis contribuições do design e suas ferramentas durante o processo de elaboração de soluções em pequena escala, por meio do surgimento de uma ação específica que fez parte do processo criativo de um produto de design que será especificado nos resultados desse artigo como ponto de partida para as reflexões da relevância do trabalho coletivo e da expressão de significados nas soluções encontradas. Destaca-se a contribuição das reflexões desse tema para a inclusão da cidade de Caruaru nesse novo formato econômico em que criatividade e a conceituação de sentidos são vistas como peças fundamentais para o desenvolvimento, apontando o importante papel do design na identificação dos possíveis caminhos para dinamizar, expressar e comunicar essas novas habilidades e propósitos das marcas, agora mais voltadas ao coletivo e a cocriação de soluções.

Palavras-chave. Economia Criativa; Design Estratégico; Design Social, Empreendedorismo feminino; Inovação. 


\section{Introdução}

A cena empreendedora contemporânea apresenta um movimento ligado à inovação e a busca por cada vez mais soluções para exprimir significados coletivos e contribuir com as necessidades humanas. Essa movimentação circular, em busca da geração e do consumo por identificação, tem demandado ferramentas mais práticas, criativas, dinâmicas e focadas em evidenciar o diferencial dos projetos e negócios.

Diante desse movimento, apenas apresentar produtos de qualidade não é mais suficiente, as marcas necessitam agora expressar significados e altos níveis de identificação com o consumidor para que haja um estreitamento entre a percepção da necessidade e o poder de decisão da compra entre os atores envolvidos ligados à sociedade, aos produtores e aos propagadores da ideia. De acordo com Gurgel (2004), "cada vez mais o conhecimento e a tecnologia assumem papel estratégico no processo de desenvolvimento econômico. ". São necessárias novas perspectivas criativas que resultem em soluções transformadoras e eficazes. Nesse quadro o autor afirma ainda que "a capacidade de inovar se tornou um dos fatores mais relevantes na determinação da competitividade das empresas e da economia em geral. ".

Desde as reflexões de autores como Löbach (2001), três funções principais materializam os produtos, a função prática, voltada a configuração dos artefatos e sua funcionalidade; a função estética, ligada aos envoltórios pensados para apresentar e expressar a solução para o mundo e a função simbólica, que resulta das duas anteriores junto à interação do usuário e abre o leque de oportunidades para a inserção de significados que de fato irão gerar a identificação do usuário com o produto. Considerando a particularidade de cada uma das funções, evidencia-se a função simbólica como um ponto a ser explorado para tornar os produtos ainda mais atrativos num contexto em que a identificação por significados pode se tornar um diferencial competitivo.

De acordo com Marchi (2014), para a economia criativa, o fator simbólico é relevante por trazer uma relação implícita entre cultura, economia e sociedade, que somada a fatores de inovação induz olhares sob novas perspectivas para determinados temas, indivíduos e grupos sociais. Já para Howkins (2001) a ideia de "economia criativa se assenta sobre a relação entre a criatividade, o simbólico e a economia." Sendo assim, é possível entender que ela aproxima atividades econômicas que partem do conteúdo simbólico, incluindo a criatividade como ponto fundamental na produção de serviços e produtos.

$\mathrm{Na}$ esfera do desenvolvimento de produtos criativos para o mercado local, o Estúdio Infinito Criativo ${ }^{1}$, fundado na cidade de Caruaru, identificou a possibilidade de reunir mulheres do universo empreendedor, que apresentam projetos com posicionamentos sociais, políticos e de consumo. Com isso surgiu o evento Fé, menina, uma feira expositiva realizada em novembro de 2016, na qual foram expostos diversos trabalhos independentes ligados a economia criativa.

Posteriormente ao evento, foi fundado um Coletivo, de mesmo nome, focado na busca por discussões e formulação de uma rede de conexão entre mulheres e as demandas geradas em seus empreendimentos. O Coletivo Fé, menina desempenha desde então pesquisas sobre empoderamento, consumo e ferramentas de design para dinamizar e direcionar, estética e simbolicamente, as soluções geradas; abrindo espaço para a mobilização social de pessoas.

Nesse sentido, o surgimento do coletivo motivou oportunidades para o fortalecimento sobretudo do caráter simbólico da construção de produtos e reunião de marcas com propósitos similares. E o conceito de inovação naturalmente necessário a esse movimento pôde ser

\footnotetext{
${ }^{1}$ Estúdio de Design Gráfico e Ferramentas de organização. Existente desde 2015, o Estúdio lançou uma linha de papelaria organizacional que teve como tema de sua primeira coleção o empoderamento feminino, o lançamento da coleção deu origem a Feira Expositiva chamada Fé, menina. Que reuniu outras mulheres da cena empreendedora na Economia Criativa Local em Caruaru. https://infinitocriativo.com.br/ I

https://ergconsultoria.com.br/feira-de-economia-criativa-agita-caruaru/
} 
impulsionado na prática por ferramentas pertencentes ao design. Como será evidenciado na conceituação do design estratégico e design social, a existência de contribuições para os desafios existentes nas etapas que permeiam desde a criação e gestão de uma ideia até a execução e interação com os diversos atores sociais.

O desenvolvimento da economia criativa, vem proporcionando oportunidades e reconhecimento para diversas regiões, assim como um novo olhar para a geração de negócios no mercado. Segundo Krucken (2009), compreendendo a importância do princípio de valorização de identidades das soluções locais, um produtor se aproxima mais assertivamente do propósito de suas ações, em consequência disso valoriza o produto ou solução que ali será ofertado.

Desse modo, o incentivo à produção local pode contribuir para consolidar aos poucos a propagação de uma nova cultura de valorização. A mencionada autora traz alguns pontos essenciais, que são orientados à valorização de produtos e territórios locais, tais como: Reconhecer as qualidades do produto local; ativar as competências locais; comunicar o produto local; proteger a identidade local e seu produto material e imaterial; apoiar a produção e promover sistemas de produção e consumo sustentáveis; desenvolver produtos e serviços que valorizem o território e proporcionar a formação de rede sociais locais.

A identificação desses pontos pode auxiliar diretamente nas possíveis ferramentas que o designer é capaz de atuar, por meio de estratégias que contribuam com os novos parâmetros de negócios. Assim, as ações de design ligadas à gestão e comunicação podem apresentar resultados para além de melhorias configurativas, como por exemplo, empoderamento de grupos, reconhecimento de capacidades complementares de distintos perfis, ampliação de redes de conexão e contatos, integração social e inovação agregada a variados processos e sistemas.

Desse modo, a importância de Caruaru-PE para o setor econômico por meio do Polo de Confeç̧ões do Agreste de Pernambuco e as atividades culturais, sociais, tecnológicas e políticas presentes nesse ecossistema, semeiam um campo fértil ao empreendedorismo. Assim como a relevância ainda maior da contribuição deste cenário empreendedor para as iniciativas de Economia Criativa protagonizadas por mulheres como um fator de inclusão e posicionamento social, trazem um grande significado para o aprofundamento do estudo e o entendimento das possíveis contribuições do design nesse caminho.

Por fim, a confiança no design como uma porta para mudar a visão de mundo das pessoas, como um agente transformador de desafios em oportunidades através da geração de conhecimento, fazendo-se importante a presença dessa dimensão nos processos de inovação de um negócio, sobretudo, conforme Barbosa (2016), um pequeno negócio que represente inovação e criatividade. Conclui-se que existe um movimento ligado a inovação geral e consequentemente local, que demanda ferramentas práticas e criativas que evidenciem o diferencial dos projetos atuais, dentre essas demandas algumas ferramentas pertencem ao design.

\section{Procedimentos metodológicos}

Foi realizada uma pesquisa bibliográfica conforme Marconi e Lakatos (2010), conduzida pelas linhas mais recentes que abordam o entendimento dos temas tratados, como: Empreendedorismo geral e empreendedorismo feminino; Economia Criativa; Design e suas vertentes; Gestão do design e inovação, para entendimento e domínio do estado da arte da problemática abordada, assim como a comparação ou identificação do conteúdo empírico adquirido e descrito no presente artigo. 
Foram realizadas buscas tanto por fontes bibliográficas tradicionais quanto por portais acadêmicos e de pesquisas digitais, como o Google Acadêmico, o Scielo e o Portal de Periódicos da CAPES e seu repositório de teses, dissertações e artigos científicos que versam sobre os conceitos aqui abordados.

Realizou-se ainda, de acordo com as definições da metodologia do estudo de caso descrita em Yin (2010), uma sintetização da pesquisa exploratória do Coletivo Fé, menina, para mapeamento de informações das mulheres empreendedoras que protagonizam o grupo situado em Caruaru, campo proveniente para a expansão dos negócios ligados à Economia Criativa Local, através de ambientes e espaços que propaguem o crescimento de negócios inovadores o posicionamento de mulheres como líderes desses negócios, como é o caso das lojas colaborativas e das feiras livres. Traçou-se dessa maneira, uma trajetória metodológica também de base exploratória, tendo em vista a proximidade com as experiências empíricas aqui mencionadas e a necessidade de entendimento de um grupo em específico também mencionado nas descrições deste artigo.

Ainda de acordo com Yin (2010), o método estudo de caso proporciona a imersão em cenários específicos para aquisição de conhecimento amplo e detalhado, trata-se, portanto, da busca aprofundada por características de determinado fenômeno, como se configura os desafios enfrentados por mulheres no cenário dos negócios inovadores contemporâneos. Os dados de experiência empírica descritos serviram de base para um levantamento qualitativo de informações e em seguida o esclarecimento das possíveis contribuições do design nesse processo.

\section{Novos formatos para o empreendedorismo contemporâneo}

As mudanças identificadas no cenário do empreendedorismo brasileiro têm contemplado diversas camadas da sociedade. Pode-se considerar o empreendedorismo e suas vertentes como delimitador de novas e variadas oportunidades, entre iniciativas de gestão, relacionamento, comercialização e comunicação. Diante das novas formas de consumo e da democratização do acesso a tecnologias de produção de bens e informações, os indivíduos podem cada vez mais gerar, testar e produzir suas ideias.

De ambientes criativos e de experimentação surgem modelos de negócios inovadores que atendem necessidades de nichos específicos ou de grandes mercados. Nesse contexto, a conceituação de empreendedorismo cunhada por Schumpeter (2002), corrobora a inovação como principal vertente. O empreendedor é identificado como alguém que se apropria de distintos formatos e recursos e os desloca de seu uso tradicional para novas aplicações, assim como realiza a busca por ferramentas estratégicas que favoreçam essa inovação.

No cenário em que a inovação é um diferencial competitivo, os modos de se relacionar com o mercado, comunicar visões e gerir seus recursos podem ser transformadores e de fato posicionar empresas como inovadoras no mercado. Compreendendo assim a criatividade como um recurso administrável, que envolve profissionais, objetivos e políticas de uma organização.

Sendo assim, faz-se necessário considerar o cenário da Economia Criativa como essencial para o entendimento do empreendedorismo contemporâneo por sua forte ligação com princípios e demandas de inovação, seja em processos, sistemas ou materializações diversas. E nesse sentido, compete ao design contribuir dinamicamente para os desafios existentes nas etapas que podem compor desde a criação de uma ideia até a execução e gestão dela como negócio. 


\subsection{A Economia Criativa como campo para visibilidade do empreendedorismo feminino.}

Paralelamente ao crescimento de meios para empreender na atualidade, cresce o número de mulheres no cenário empreendedor. Gonçalvez (2016), compreende e aponta em seus estudos a década de 1990 como marco da inserção e expansão da mulher no mercado de trabalho, resultante das várias transformações econômicas que denotam o início dessa visibilidade.

O Instituto de Geografia e Estatística - IBGE (2016), apresenta a população feminina como mais da metade da população brasileira (50,57\%) e desse percentual $59,70 \%$ estão economicamente ativas e aptas a trabalhar, sustentar ou contribuir para o sustento de lares, o que é equivalente a mais de 60 milhões de mulheres com possibilidade real de ingressar direta ou indiretamente no cenário empreendedor. Para Gomes (2010), muitos estudos precedentes ao século XXI, sobre a ascensão da mulher no mundo dos negócios, buscaram compreender sua condição e capacidade empreendedora comparada aos homens.

Nesse sentido, desde a década de 1970 evidenciaram-se investigações acerca do "empreendedorismo feminino", desde o entendimento do perfil da mulher empreendedora até estudos que analisam aspectos pessoais, psicológicos, demográficos, etários, educacionais, cognitivos, motivacionais, sociais e outros ligados à condição de gênero. Contudo é perceptível em linhas gerais que as pesquisas realizadas não conotavam grandes diferenças nas motivações de características empreendedoras de homens e mulheres para além de fatores culturais e não como era suposto nos estudos iniciais por fatores biológicos.

De acordo com Howkins (2001), do ponto de vista econômico, "a economia criativa é um conjunto de segmentos dinâmico, cujo comércio mundial cresce a taxas mais elevadas do que o resto da economia". Esse tipo de atividade somada ao fortalecimento de debates sobre o protagonismo feminino e empoderamento em diferentes aspectos, fortalece a geração de projetos e negócios criados por mulheres e pode gerar novas fontes de renda em diferentes segmentos, contribuindo assim para um crescimento da região e também a disseminação de ideais e inserção da mulher no mercado como empreendedora e propagadora de posicionamentos.

\section{Possíveis contribuições do Design aos novos formatos do empreendedorismo}

Para Consolo (2015), o design tem como objetivo central identificar problemas ou necessidades e, a partir de observações, propor melhorias que facilitem as interações dos indivíduos em relação ao meio. Martins (2014) reforça ao afirmar que "a construção de significados é inerente a atividade projetual do design" e está presente em todo o processo de geração de ideias e construção de resultados.

Desse modo, o consumo de informação de design, que antes se pautava de forma mais evidente em um apelo visual, hoje se torna mais profundo e traz os significados criados por trás da marca por meio da materialização dos artefatos e da geração de experiências. Consolo (2015) traz o branding, como uma ferramenta para construir e manter os valores e significados de uma empresa na mente do consumidor. A partir dessa afirmação, entende-se que essa construção está intrinsecamente ligada à cultura criativa da organização sendo realizada coletivamente para então ser comunicada de forma íntegra e coerente por meio de ferramentas estratégicas do design.

Esse alinhamento reforça a ideia de que, em empresas da área da economia criativa, aliar um modelo flexível de gestão e o uso do design como ferramenta de inovação pode potencializar os simbolismos, a geração de identificação e consequentemente o seu desenvolvimento. Bezerra (2016) aponta que a união do branding como modelo de gestão e o uso do design estratégico em diferentes setores de uma empresa: 
resultado, o produto torna-se diferenciado, amplificando seu valor financeiro e simbólico e a exposição e valorização da sua localidade de origem.

Ainda sobre o simbolismo, ao observá-lo através da criatividade e inovação, Marchi (2014) afirma:

Partindo do princípio de que a criatividade tornou-se a chave para a promoção de um novo desenvolvimento, socialmente inclusivo, ecologicamente sustentável e economicamente sustentado, fomenta diferentes setores produtivos que possuem como denominador comum a capacidade de gerar inovação a partir de um saber local, agregar valor simbólico a bens e serviços, além de gerar e explorar direitos de propriedade intelectual

Nesse processo o design estratégico atua no alinhamento entre os direcionamentos estratégicos da organização e a criação de seus produtos, serviços e formas de comunicação. Isto posto, estratégias são essenciais na condução de uma empresa aos seus objetivos; elas permeiam tudo que envolve a marca e o valor percebido pelos indivíduos. Para Bezerra (2016), a inclusão do design em empresas pode ser feita em três níveis: operacional, gerando valor na criação do produto; funcional, estruturando equipes e estratégico, para ações de planejamento.

Já no Design Social, defendido desde Victor Papanek em (1971) evidencia-se a contribuição direta com as mobilizações que tangenciam atividades coletivas ou complementares na sociedade e portanto a responsabilidade demandada pelas configurações dos artefatos e das soluções imateriais desempenhadas coletivamente seja em organizações empresariais ou em mobilizações sociais diversas.

Na visão de Carvalhal (2016), compreender o fenômeno criativo em detrimento das ações empreendedoras contemporâneas é condição ímpar para classificar os novos formatos de negócio. Trata-se de uma evidenciação da cultura e da economia como uma extensão da construção de sentidos para os artefatos: "O valor que antes tinha origem nos bens homogêneos, reprodutíveis e no tempo controlado, agora se localiza justamente na mudança e na inovação, independente de qual setor da economia".

Pontua-se ainda, a importância do desenvolvimento do entorno criativo e o entendimento de todos os benefícios que este universo pode oferecer de maneira coletiva, não sendo papel isolado do design a busca por soluções, mas agora muito mais pelas ações que proporcionem colaboração em ações e ideias. Para Bonsiepe (2011), a direcionamento de ações que aproximem as pessoas é também tarefa primordial para o designer contemporâneo, uma vez que as estratégias antes pensadas para representar soluções individuais, hoje auxiliam o desenvolvimento do todo e da coparticipação de atores de diversas camadas da sociedade.

Com isso, o design social é uma importante área frente às demandas de coletivos ligados à economia criativa. Na visão de Bürdek (2006), o design compreende uma dimensão muito além da materialização dos artefatos e diz respeito ao planejamento, o emprego de sentidos e, principalmente, as adaptações culturais presentes em cada contexto de inserção. Segundo Cardoso (2004), o design consiste em ideia, projeto ou plano para solucionar determinado problema e compreende principalmente o processo de configuração das soluções.

Considerando as afirmações acima, o design como um ato cerebral se relaciona com o empirismo, ou seja, tudo aquilo que está diretamente ligado ao sensorial, seus anseios, seu tempo, seu espaço, suas percepções e experimentações. Desse modo, as observações empíricas do cotidiano dos indivíduos abrem para o design a capacidade de inovar e contribuir com soluções mais eficazes.

E ainda, conforme Manzini (2008), a inovação que parte do contexto social e colaborativo, viabiliza modificações que indivíduos ou comunidades estão dispostos a assumir em busca de novas oportunidades em oposição a antigos problemas; tais mudanças propiciam conquistas 
diversas e fortalecem a validação e valorização do contexto local, irrompendo os padrões atuais da indústria da produção através de novos aprendizados e formações sociais participativas, de ganhos simultâneos, como reflexos de ações locais centradas no problema. Desta forma, compreendendo as necessidades que surgem no dia-a-dia da comunidade ou grupo, tratadas por Manzini como "Comunidades Criativas".

Na visão de Brown (2010), às mudanças presentes nos formatos de gerenciamento das empresas, sobretudo ligadas ao conceito de inovação evidenciam o design não mais como um elemento apenas consultado no final do percurso de desenvolvimento do produto, mas como parte fundamental na estruturação desse desenvolvimento, transcendendo o tangível e se relacionando cada vez mais com o experiencial:

À medida que o centro da atividade econômica no mundo em desenvolvimento foi passando inexoravelmente da produção industrial à criação de conhecimento e prestação de serviços, a inovação se tornou nada menos do que uma estratégia de sobrevivência. Além disso, ela não se limita mais ao lançamento de novos produtos físicos, mas inclui novos tipos de processos, serviços, interações, formas de entretenimento e meios de comunicação e colaboração. Esses são exatamente os tipos de tarefas centradas no ser humano nas quais os designers trabalham todos os dias. A evolução natural de fazer design a pensar design reflete o crescente reconhecimento por parte dos líderes de negócios do que o design se tornou importante demais para ser deixado exclusivamente aos designers (BROWN, 2010, p.7)

Em sua pesquisa, Moroni (2016) apresenta cinco processos de design presentes em embasamentos teóricos que consideram os caminhos para o fomento do empreendedorismo e da inovação em empresas, o citado estudo é focado em startups ${ }^{2}$, porém claramente compreensível e próximo ao cenário da economia criativa. São eles: "Design para estratégias de inovação", "Design para geração de ideias", "Design para a criação de conceitos", "Design para representação da empresa", "Design como integrador". Em cada um desses processos é possível perceber as possibilidades de conexão e atuação do designer diante da dinamicidade dos desafios do empreendedorismo sob a ótica da inovação criativa.

Por fim, conforme Bonsiepe (2015), os encaminhamentos metodológicos de design proporcionam maior assertividade às soluções geradas, além de diferenciar a área de outras searas criativas mais gerais. Compreende-se desse modo, a relevância das estratégias do design para o cenário da Economia Criativa.

\section{Resultados e discussões - O Caso do Coletivo Fé,Menina}

Diante do cenário construído nas etapas anteriores, em que a criatividade e a inovação apresentam-se como diferenciais competitivos e ressignificar práticas locais representa novos formatos de atuação no mercado, esse artigo traz o exemplo do Coletivo Fé, Menina.

O Estúdio Infinito Criativo, uma empresa inserida no setor da economia criativa, desenvolve projetos nas áreas de design gráfico e produto. Está situado em Caruaru, uma cidade inserida em uma região rica culturalmente que tem entre as principais atividades econômicas a indústria e o comércio. Fundado em 2015, o estúdio traz como valores, traços do novo movimento da economia como a priorização da criatividade, inovação e construção de significados, tendo como principal ferramenta o uso do design de forma estratégica.

\footnotetext{
2 Uma startup é uma empresa ou projeto de negócio emergente, geralmente de base tecnológica, que busca desenvolver ou aprimorar ideias ligadas a inovação. Geralmente essas empresas iniciam sua vida útil no interior de grandes aceleradoras e incubadoras empresariais. (MORONI, 2016)
} 
Originalmente a atividade do citado estúdio era o desenvolvimento de marcas e projetos gráficos, no entanto, durante um processo de capacitação das fundadoras, encontrou-se nos campos da gestão e planejamento, conceitos que somados ao design e seus caminhos visuais deram origem a um projeto que resultou na realização de um evento em formato de Feira expositiva e reuniu mulheres atuantes do cenário da economia criativa de Caruaru.

A ideia que encadeou a realização da mencionada feira veio do desenvolvimento de um produto de design que tinha como tema, o empoderamento feminino. Na ocasião, o Estúdio Infinito Criativo realizou a comemoração de seu primeiro ano de existência com o lançamento de uma linha de artigos de papelaria, planejada para auxiliar as pessoas na organização pessoal e profissional do seu dia a dia. Essa nova linha de produtos foi incorporada às atividades da empresa, dando origem a construção de um novo segmento para comercialização. Após a construção do processo criativo, foram traçadas ações para a divulgação e compartilhamento dos produtos, desencadeando a criação de um evento que reunisse mulheres empreendedoras para compartilhar seus trabalhos, logo, o lançamento da coleção "empodere-se", que abriu espaço para mais mulheres da cena empreendedora local.

Quanto ao formato da ação, a organização de uma feira objetivou reunir pessoas ao ar livre para ocupar um espaço urbano com atividades culturais e comercialização, formato semelhante a um dos principais pontos turísticos e atividade econômica da cidade: a feira de Caruaru. De acordo com Miranda (2009), as feiras fazem parte da raiz econômica das cidades e contribuem para a construção das relações humanas e comerciais, sendo assim o formato torna-se estratégico para a construção de redes sociais locais entre indivíduos e marcas que partilham do mesmo posicionamento. A autora enfatiza essa relação de comércio, socialização e cultura ao afirmar que "As feiras fazem parte da vida das cidades, em especial nas nordestinas, pois mantêm com elas uma ligação íntima e simbiótica, através da ocupação do espaço urbano, do colorido e da diversidade dos produtos vendidos, das relações humanas e da riqueza cultural".

A primeira edição da Fé, Menina como feira expositiva reuniu 25 marcas criadas por mulheres, com produtos em segmentos distintos que englobavam: ilustração; decoração; vestuário consciente e sem gênero com marcas que utilizam a atividade de confecção local resinificando os processos produtivos e de consumo; jardinagem; gastronomia; acessórios de moda; acessórios para bebê; livros independentes; entre outros.

Entre os produtos apresentados, a existência de artefatos que traziam o uso de técnicas tradicionais da região aliadas a tendências visuais modernas aplicadas em objetos de uso cotidiano, como camisas criadas a partir de pintura manual e objetos de madeira pintados com canetas inspirados na técnica da xilogravura, por exemplo. Durante a realização do evento, outras atividades também foram realizadas como debates e apresentações culturais simultâneas.

Buscou-se reunir empresas que estivessem inseridas na economia criativa e que aplicassem no seu produto, seja nos processos de construção, confecção ou comunicação, a criatividade e o seu posicionamento, gerando um diferencial e construindo laços com seu público consumidor. Reunindo dessa maneira, marcas que possuem características semelhantes as ações idealizadas e fomentam a visibilidade para a mulher empreendedora, buscando também valorizar o fator simbólico como aliado ao conceito trazido pela economia criativa, como algo ligado a maior exclusividade e aproximação com o público, assim como valorizando a produção "glocal", conforme pontua Bonsiepe (2011) e Manzini (2008).

A repercussão do evento foi bastante positiva e alcançou um objetivo não identificado durante seu planejamento, a sua propagação para mais ações de cunho político, social e também cultural para a cena empreendedora feminina de Caruaru. Desse modo, após a repercussão da 
Feira, foi idealizado e posto em prática, o Coletivo Fé, Menina, que passou a realizar eventos e encontros periódicos para impulsionar a economia criativa feita por mulheres localmente e em consequência disso, comunicar essas ações para a comunidade local.

\subsection{Ferramentas de design para o Coletivo Fé, menina.}

Até o presente momento foram realizadas 3 mostras criativas, uma por ano, e mais de 40 marcas participaram de alguma atividade proposta. A partir de feedbacks sobre as edições, foram incorporadas mesas redondas às programações, com o objetivo de promover debates sobre temas relacionados ao empreendedorismo feminino e a economia local.

Dentre as empresas identificadas ao decorrer do desenvolvimento do projeto, destacam-se alguns exemplos para maior contextualização, como: a marca "O Inventário"”, que utiliza técnicas de marcenaria e xilogravura para criar peças de decoração com mensagens e ilustrações que geram identificação pela cultura local aliadas a novas tendências de decoração; a marca "Las Lobas Ateliê", que produz peças de vestuário e acessórios, que incluem em sua construção o posicionamento da empresa, visando a sustentabilidade, a autonomia da mulher e a produção livre de exploração. Ao destacar em sua comunicação o processo de produção, seus posicionamentos políticos e sociais e construir coleções com conceitos que se relacionam com os temas debatidos, internamente e coletivamente, o ateliê gera identificação com um público que partilha dos mesmos ideais e se utiliza da construção de significados por meio dos aspectos simbólicos do produto, aplicando assim o design de forma estratégica.

Quanto as ferramentas de design presentes na estruturação tanto do movimento de modo geral, quando na organização de tudo que é discutido, pensado, produzido e comunicado coletivamente, destacam-se:

- Ferramentas de cocriação, em que o desenvolvimento dos projetos passa por um acompanhamento e coleta de sugestões coletivas para melhoramentos no processo criativo ou durante o processo final para os encaminhamentos de comunicação;

- Ferramentas de organização e auxílios visuais, desde o auxílio na elaboração de linguagem para as marcas até a reapresentação de material visual, passíveis de dinamizar as várias atividades das mulheres ligadas ao coletivo e consequentemente de cada empresa, como quadros de distribuição de tarefas ou execução de etapas, por exemplo;

- Ferramentas de organização de processos, em que todas as etapas do desenvolvimento criativo das peças passam por encaminhamentos de organização e hierarquização de etapas necessárias à sua conclusão;

- Gestão do Design, com pontos de gestão compartilhada e coletiva que impulsiona um gerenciamento mais livre e fluido das etapas que pertencem a um negócio, de sua idealização até sua apresentação no mercado.

- Construção da linguagem visual e marca para o evento e posteriormente para o coletivo, em que foram realizadas pesquisas com o público e o seu consumo de informação visual, para assim gerar peças que se tornassem atrativas e comunicassem a ideia do evento.

As ferramentas descritas foram apresentadas nos encontros das marcas que formam o coletivo e postas em prática nas ações conjuntamente pensadas, a princípio internamente para articulação do próprio grupo, desde a criação da linguagem nas redes sociais e o posicionamento em eventos na cidade até a integração e conexão do discurso das participantes durante a

\footnotetext{
${ }^{3}$ Loja de virtual de artigos de decoração conceituais - http://www.oinventariodecora.com.br
} 
exposição dos produtos comercializados. Em sequência se configura um movimento atual para aplicação delas individualmente com as marcas, sendo o principal desafio lançado.

\section{Considerações finais}

Diante das ferramentas já testadas e do planejamento de aplicações individuais que são passíveis do auxílio do design e suas vertentes, pode-se evidenciar o potencial de contribuição deste para a formação de uma ideologia de compartilhamento de processos e apresentação de resultados com foco na geração de diferenciais e significados para as marcas envolvidas. Esta condição apresenta ainda a possibilidade de agregar valor ao grupo atraindo outras marcas do cenário da economia criativa local.

Semear design e suas vertentes mais dinâmicas para o desenvolvimento criativo e as oportunidades de inovação presentes na cidade de Caruaru tem sido cada vez mais necessário. A ideia central do conceito de economia criativa desde o seu surgimento é a tentativa de mensurar o valor da produção criativa. A definição da economia criativa e sua apropriação de pequenas ideias de valor foi um importante passo na indústria de consumo; a partir dela tornou-se possível o estabelecimento de soluções inovadoras para os mais diversos cenários e mercados.

No que tange ao design e a economia criativa local, a criação do evento que deu origem ao Coletivo Fé, menina, contribuiu para a construção de valores dentro de um grupo social, que de alguma forma foram associados as ações realizadas por um grupo de empresas e os produtos por elas desenvolvidos e mais ainda a construção de significados e consequente identificação que partiu desse contexto de modo geral.

Para além da construção do produto, foi evidenciada a importância do posicionamento estratégico por meio de ferramentas de design como o planejamento visual de coleção, geração de conteúdo visual direcionado para o público avaliado e consequentemente, a geração de identificação do público com o posicionamento criado. Essa percepção evidencia a urgência por projetos e ideias que privem a inserção de simbologias em seu desenvolvimento, que sejam capazes de aproximar pessoas ou grupos que apresentem ideais semelhantes. Como em Howkins (2001), as bases da economia criativa se apoiam hoje em processos que busquem uma relação entre inovação, criatividade, simbolismo e compartilhamento.

O Coletivo Fé, Menina contribui para o desenvolvimento local de Caruaru e região em aspectos econômicos, criativos e sociais, e para a inserção da região em um movimento global, reunindo e impulsionando de forma coletiva marcas locais que produzem e ressignificam artefatos. No que diz respeito a criatividade, expõe produtos com técnicas de produção e comunicação inovadoras, e aproxima essa renovação produtiva de indivíduos locais.

Socialmente, por se tratarem de ações voltadas para mulheres empreendedoras contribui ainda na formação de uma rede social que promove o empoderamento por meio da independência financeira, além de fomentar a produção local de uma forma geral, gerando debate acerca de consumo, da remuneração ou condições de trabalho. Por reunir marcas que compartilham de ideologias, políticas e sociais, o movimento passou a relacionar pessoas e criar redes sociais a partir do seu caráter simbólico.

Idealizado para expressar a autonomia de reflexões sobre o tema empoderamento feminino, sobretudo por meio do empreendedorismo local, o que inicialmente foi exposto a sociedade como uma feira ou mostra criativa, resultou num grupo que realiza encontros e eventos periodicamente para discutir soluções compartilhadas ligadas ao cenário empreendedor e as demandas desse universo, assim como tem se tornado campo fértil para a exploração de ferramentas que incorrem o universo do design para dinamicidade do mercado atual. 


\section{Referências}

BARBOSA, L. C. Aprendizagem organizacional na economia criativa: um processo social a partir da atuação dos gestores. Dissertação apresentada ao Programa de Pós-Graduação em Administração, UFPE, 2016. (https://repositorio.ufpe.br/handle/123456789/18578).

BEZERRA, P. F. M. Design estratégico e branding: valorizando experiências e produtos locais - o caso Sambazon / Pablo Felipe Marte Bezerra. - Recife, 2016. 228 f.: il., fig.

(https://repositorio.ufpe.br/handle/123456789/28973

BONSIEPE, G. Do material ao digital. São Paulo: Blucher, 2015.

. Design, Cultura e Sociedade. São Paulo: Blucher, 2011.

BROWN, T. Design Thinking: Uma metodologia poderosa para decretar o fim das velhas ideias. Rio de Janeiro: Elsevier, 2010.

BURDEK, B. E. Design: história, teoria e prática do design de produtos. São Paulo: Blücher, 2006.

CARDOSO, Rafael. Uma introdução à história do design. 3a ed. São Paulo: Edgard Blücher, 2008.

CARVALHAL, F. No caminho para uma gestão criativa: A percepção dos gestores da Economia Criativa sobre suas Experiências. Dissertação apresentada ao Programa de Pós Graduação em Administração da Universidade Federal de Pernambuco, Recife - 2016. Disponível em

(https://repositorio.ufpe.br/handle/123456789/18949)

CONSOLO, Cecília. Marcas: Design estratégico: Do Símbolo à Gestão da Identidade Corporativa. São Paulo. Blucher 2015.

ERG Consultoria. Feira de Economia Criativa agita Caruaru. Disponível em: (http://ergconsultoria.com.br/feira-de-economia-criativa-agita-caruaru).

FLORIDA, R. The rise of the creative class. Washington monthly, May 2002.

GOMES, A. F. Ação empreendedora e relações de gênero: Um estudo multicasos na cidade de Vitória da Conquista, Bahia. Tese apresentada ao Programa de Pós Graduação em Administração da Universidade Federal de Lavras - Minas Gerais, 2010. Disponível em: (https://bit.ly/2UpQEBM)

GONÇALVES, K. L. F. Empreendedorismo feminino: fatores de influência na gestão eficiente. Dissertação apresentada ao Programa de Mestrado em Engenharia de produção do UNIPUniversidade Paulista. 2016. Disponível em:

(https://www.unip.br/presencial/ensino/pos_graduacao/strictosensu/eng_producao/download/e ng_kellyfonsecagoncalves.pdf)

HOWKINS, J. The Creative economy : how people make money from ideas. [S.1]. Penguin, 2001.

IBGE - Instituto Brasileiro de Geografia e Estatística. Disponível em: (http://www.ibge.gov.br).

KRUCKEN, Lia. Design e território: Valorização de identidades e produtos locais. São Paulo: Studio Nobel, 2009.

LAKATOS, E. M.; MARCONI, M. D. Fundamentos de Metodologia Científica. São Paulo: Atlas, 2010.

LÖBACH, B. Design Industrial. Bases para a Configuração dos Produtos Industriais, Blucher - 1a ed., São Paulo, 2001.

MANZINI, E. Design para a inovação social e sustentabilidade: comunidades criativas, organizações colaborativas e novas redes projetuais. Rio de Janeiro: E-papers, 2008.

MARCHI. Leonardo de. Análise do Plano da Secretaria da Economia Criativa e as transformações na relação entre Estado e cultura no Brasil. Intercom - RBCC São Paulo, v.37, n.1, p. 193-215, jan./jun. 2014. Disponivel em http://www.scielo.br/pdf/interc/v37n1/a10v37n1.pdf 
MARTINS, Gabriela. Território inovativo: proposta de modelo de desenvolvimento de território inovativo aplicado ao APL de confecções do Agreste. Disssertação apresentada ao Programa de Pós Graduação em Design da Universidade Federal de Pernambuco. Disponivel em (https://repositorio.ufpe.br/handle/123456789/13207)

MIRANDA. Gustavo. A feira na cidade: limites e potencialidades de uma interface urbana nas feiras de Caruaru e de Campina Grande. Dissertação apresentada ao Programa de Pós Graduação em Desenvolvimento Urbano. Disponível em: (https://repositorio.ufpe.br/handle/123456789/3220)

MORONI. I.M.R. Como os processos de design podem contribuir para o desenvolvimento da capacidade inovadora nas empresas startups: um estudo sobre o Porto Digital. Dissertação apresentada ao Programa de Pós-Graduação em Design da Universidade Federal de Pernambuco. Disponível em: (https://repositorio.ufpe.br/handle/123456789/21700).

PAPANEK, Viktor. Design for the Real World: Human Ecology and Social Change. New York: Van Nostrand Reinhold, 1971.

SCHUMPETER, J. A. Economic theory and entrepreneurial history. Revista Brasileira de Inovação, Rio de janeiro, v.1, jul./dez. 2002.

YIN, Robert. Estudo de caso: planejamento e métodos. Porto Alegre. 4ạedição. Editora: Bookman, 2010. 